\title{
Chronic postcataract endophthalmitis caused by Penicillium species in an immunocompetent patient
}

This article was published in the following Dove Press journal:

International Medical Case Reports Journal

\section{Koji Kanda' \\ Kei Takayama' \\ Toshio Enoki² \\ Masaru Takeuchi' \\ 'Department of Ophthalmology, National Defense Medical College, Tokorozawa, Japan; ${ }^{2}$ Enoki Eye Clinic, Sayama, Japan}

\begin{abstract}
Objective: Penicillium species are abundant, generally saprophytic, and widely distributed in the environment. On rare occasions, they cause endophthalmitis in immunocompromised patients or in immunocompetent patients with uncontrolled diabetic mellitus or immunosuppressive agents. We report a case of endophthalmitis caused by Penicillium species in an immunocompetent patient without any disorders.
\end{abstract}

Case presentation: A 67-year-old woman presented with ocular pain, hyperemia, and blurred vision in her right eye. She was in an immunocompetent condition and had received cataract surgery without complications 3 months ago. Severe cell infiltration and a clump of $3 \mathrm{~mm}$ diameter were found in the anterior chamber of the right eye, and there was no abnormality in the posterior segment. Serum $\beta$-D-glucan was not elevated; bacterial culture, histological analysis, and PCR using aqueous humor did not detect any pathogen (28S rDNA $2.4 \times 10^{2}$ copies $/ \mathrm{mL}$ ). However, because the clinical findings suggested fungal endophthalmitis, antifungal medication was initiated. The inflammation was gradually resolved with contraction of the clump; however, it recurred 47 days after the initiation by discontinuation of antifungal medication. Examination of culture identified Penicillium species in samples from both the anterior chamber and the vitreous.

Conclusion: Chronic postoperative endophthalmitis by Penicillium species can occur in an immunocompetent patient without any systemic diseases.

Keywords: endophthalmitis, immunocompetent, Penicillium, postcataract

\section{Introduction}

Penicillium species are abundant, generally saprophytic, and widely distributed in the environment. ${ }^{1,2}$ They rarely cause disease in humans, although they are increasingly recognized as a potential pathogen in immunocompromised hosts. ${ }^{3}$ In the eye, Penicillium species can cause infectious keratitis, ${ }^{4}$ but rarely is endophthalmitis developed, even in patients who are immunocompromised or using an immunosuppressive agent. ${ }^{5}$ Exogenous fungal endophthalmitis accounts for $\sim 10 \%$ of cases of postoperative endophthalmitis and mainly occurs in immunosuppressed patients. ${ }^{6}$ Candida, Aspergillus, and Fusarium species are the most common culture-positive isolates from such patients. ${ }^{7}$ We report a case of chronic postoperative endophthalmitis after cataract surgery caused by a filamentous fungus, Penicillium species, in an immunocompetent patient without any systemic diseases.

\section{Case report}

A 67-year-old woman was referred to our department with ocular pain, hyperemia, and blurred vision in the right eye. Cataract surgery had been performed for both eyes
Department of Ophthalmology, National

Defense Medical College, 3-2 Namiki,

Tokorozawa city, Saitama 359-85I3,

Tel +8| 42995 |2 II

Fax +8I 429935332

Email keitakal23@ndmc.ac.jp 
in a clinic at 3 months ago. She had no history of systemic disease and was in an immunocompetent condition. At first presentation, best-corrected visual acuity (BCVA, measured with a standard Japanese visual acuity chart and converted to Snellen visual acuity) and intraocular pressure (IOP) in the right eye were 20/20 and $17 \mathrm{mmHg}$, but slit-lamp biomicroscopy revealed a white clump of $3 \mathrm{~mm}$ diameter, anterior inflammatory cells, and an iris posterior synechia in the anterior segment (Figure 1A and B). There was no inflammation in the posterior segment (Figure 1C). Serum examination showed a slight increase in white blood cells $\left(8,600 / \mathrm{mm}^{3}\right)$ but not in $\beta$-D-glucan $(9 \mathrm{pg} / \mathrm{dL})$ or inflammatory proteins. Bacterial culture of the anterior humor and histological analysis of the white clump did not detect the cause of the endophthalmitis. As well, increase of $18 \mathrm{~S} / 28 \mathrm{~S}$ rDNA (18S rDNA, not detected; 28S rDNA $2.4 \times 10^{2}$ copies $/ \mathrm{mL}$ ) was not presented by broad-range PCR using the aqueous humor. Because the white clumps in the anterior chamber strongly suggested fungal endophthalmitis, treatment with systemic and topical antifungal agents (systemic fosfluconazole [504 $\mathrm{mg} / \mathrm{d}, 4$ days] and topical pimaricin ophthalmic ointment [4 times/day]) was initiated in addition to antibacterial treatment (systemic cefepime [1,000 mg/d, 4 days] and topical moxifloxacin hydrochloride [6 times/day], vancomycin eyedrops
[6 times/day], and ceftazidime eyedrops [6 times/day]). These medications were tapered according to the remission of the clump and inflammation in the anterior segment. At 14 days, the endophthalmitis was resolved (Figure 1D) and the subjective symptoms had disappeared.

On day 47 after the initiation of treatment, she visited our hospital for headache, recurrence of ocular pain, hyperemia, and blurred vision in the right eye. BCVA was decreased to hand motion, and IOP was elevated to $40 \mathrm{mmHg}$ in the right eye. Slit-lamp biomicroscopy showed reappearance of a white clump in the anterior segment, anterior inflammatory cells, large iris nodules, fibrin formation, and a posterior synechia (Figure 2A). The posterior segment was not visible due to inflammation in the anterior segment. Serum examination did not present an increase in $\beta$-D-glucan. Vitrectomy was emergently performed, and the aqueous humor and vitreous humor samples were obtained. Examination of microbial culture using samples from both the anterior chamber and the vitreous identified Penicillium species. We diagnosed fungal endophthalmitis caused by Penicillium species, and treatment with systemic micafungin $(100 \mathrm{mg} / \mathrm{d}, 9$ days), oral voriconazole (200 mg/d, 9 days) and flucytosine (6,000 mg/d, 9 days), and voriconazole eye drop (4 times/ day) was initiated. The ocular inflammation by fungal

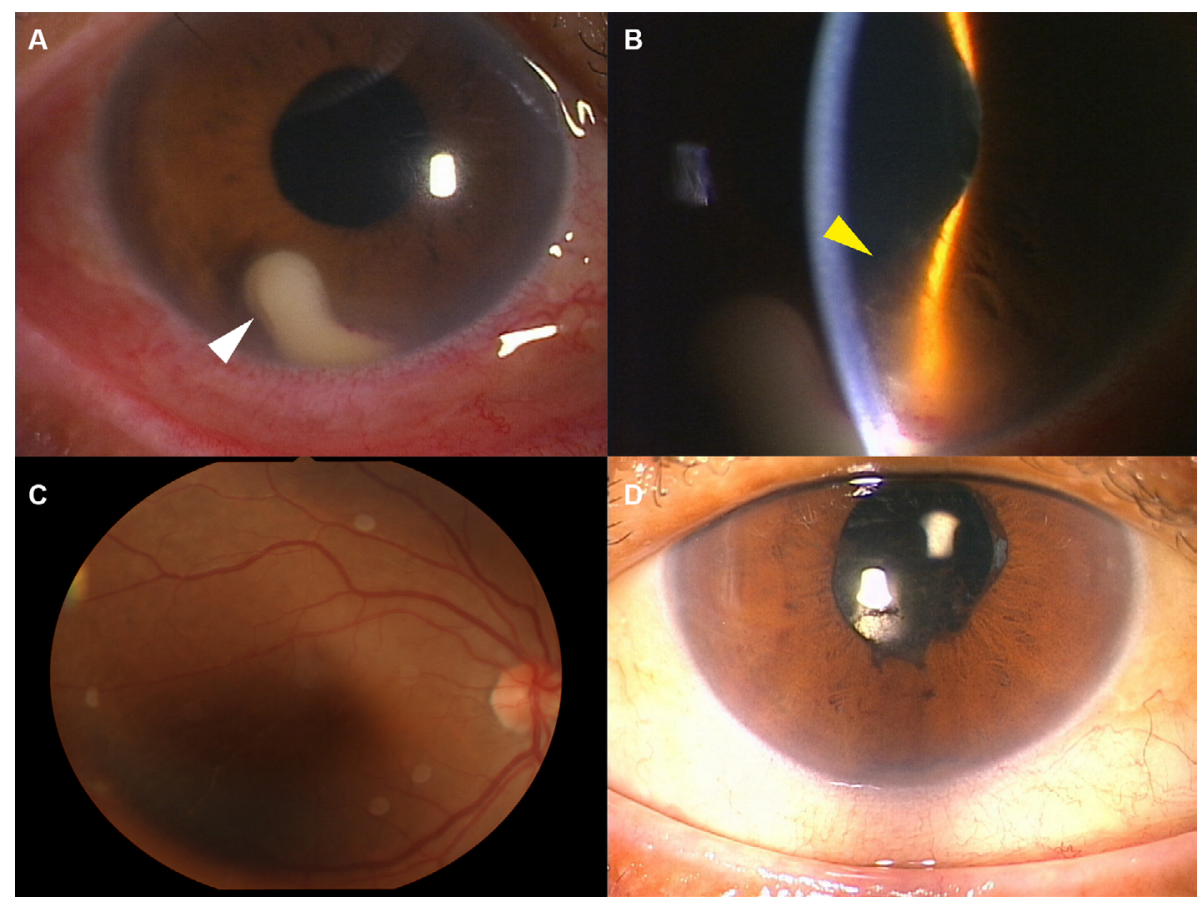

Figure I Photographs of the right eye on days I and 17.

Notes: Slit-lamp photographs (A, B, D) and a fundus photograph (C). On the first visit, a white clumped mass (white arrow head) (A), iris synechia (yellow arrow head), and inflammatory cells were seen in the anterior chamber (B), and no inflammation was seen in the posterior segment (C). After treatment, the anterior chamber showed no inflammation or white mass (D). 


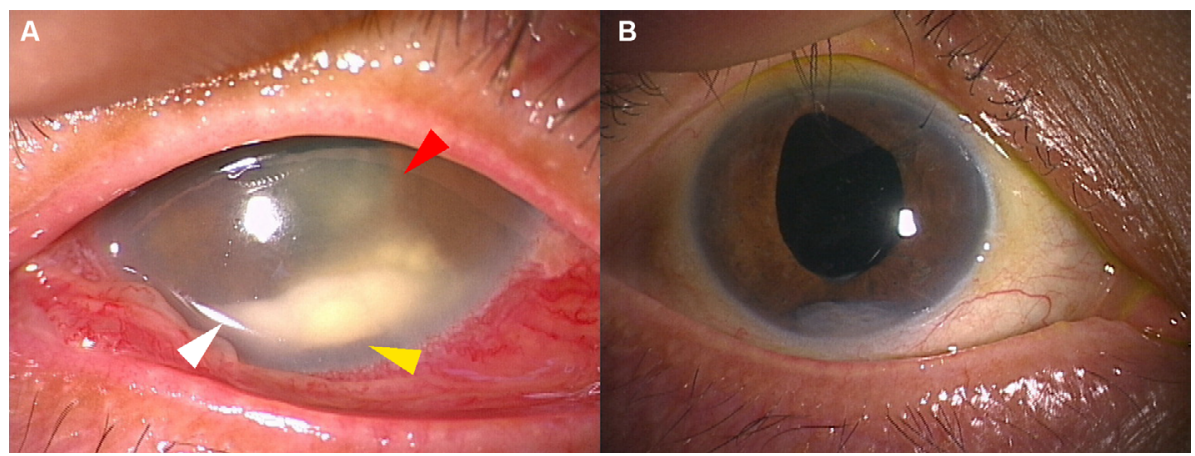

Figure 2 Anterior segment at recurrence and at the last visit.

Notes: A white clumped mass (white arrow head), iris nodule (yellow arrow head), iris synechia (red arrow head), and inflammatory cells were seen in the anterior chamber at recurrence (A). At the last visit, the inflammation and the mass were resolved, although the iris nodule remained (B).

endophthalmitis was gradually resolved with contraction of the clump after 14 days (Figure 2B), although the iris nodules remained. BCVA was improved to 20/16, and IOP was decreased to $16 \mathrm{mmHg}$. No recurrence was found 16 months after the second treatment.

\section{Informed consent}

Written informed consent has been provided by the patient for the publication of her case details and images.

\section{Discussion}

Postoperative fungal endophthalmitis shows a variable presentation, ranging from localized in the anterior chamber to more diffuse intraocular inflammation. ${ }^{6}$ The present case had a prolonged latency period, as in previous reports of fungal endophthalmitis, and followed these trends with diffuse anterior segment inflammation. The presence of iris nodules, as shown in this case, has been also documented in other cases of inflammation with fungal etiologies, including Candida, Fusarium, and Coccidioides species. ${ }^{8}$ Therefore, endophthalmitis by Penicillium species was suspected due to the clinical findings along with the latency period.

Since Penicillium species are sometimes encountered in the clinical laboratory as culture contaminants, ${ }^{9}$ diagnosis is established by histological demonstration of fungus-invaded tissue or PCR. In this case, biopsy of the iris nodules and broad-range PCR for $18 \mathrm{~S} / 28 \mathrm{~S}$ rDNA were performed, as in previous reports. ${ }^{5,10}$ However, these methods could not detect Penicillium infection. We diagnosed Penicillium species infection from the results of microbial cultures using both the anterior humor and the vitreous samples and the efficacy of antifungal agents. We set the positive threshold value in PCR for 18S/28S rDNA because a trace amount of contamination can be detected.
Fungal contamination sometimes detected by elevation of 28S rDNA by PCR using the intraocular fluids. ${ }^{11,12}$ Although $2.4 \times 10^{2}$ copies/mL of $28 \mathrm{~S}$ rDNA was detected by PCR using the aqueous humor in this case, we determined the result was negative based on these reports. However, it should be finally considered as positive.

Treatment of fungal endophthalmitis is difficult; no clear protocols exist because of the lack of well-controlled double-blind studies and the low incidence of the diseases. ${ }^{2}$ In the present case, systemic fosfluconazole and topical pimaricin ophthalmic ointment did not lead to complete remission, whereas systemic flucytosine indicated a splendid effect. For Penicillium infection in HIV patients, antifungal medication including flucytosine is selected, ${ }^{13}$ and flucytosine is highly active against Penicillium species. ${ }^{1}$ It has been also reported that flucytosine penetrates into vitreous with higher concentration than other antifungal agents, ${ }^{14}$ although the eye is a protected compartment and penetration of systemically administered antifungal agents are highly variable, particularly in the posterior segment.

\section{Conclusion}

This is a rare case of postoperative fungal endophthalmitis caused by Penicillium species in an immunocompetent patient without any systemic diseases. In these cases, if examination of microbial culture or PCR for $18 \mathrm{~S} / 28 \mathrm{~S}$ rDNA using intraocular fluids are negative, antifungal treatment based on the clinical findings should be performed, which leads to the diagnosis.

\section{Acknowledgments}

This study was funded by Grant-in-Aid for Scientific Research C (M Takeuchi, 16K11337) and Grant-in-Aid for 
Young Scientists B (K Takayama, 17K16964) from the Ministry of Education, Culture, Sports, Science and Technology (http://www.jsps.go.jp/).

\section{Disclosure}

The authors report no conflicts of interest in this work.

\section{References}

1. Randhawa PS, Nouraei SR, Howard DJ, Sandhu GS, Petrou MA. Penicillium species as a rare isolate in tracheal granulation tissue: a case series. J Med Case Rep. 2008;2(1):84.

2. Asencio MA, Huertas M, Carranza R, Tenias JM, Celis J, Gonzalez-del Valle F. A case-control study of post-traumatic endophthalmitis at a Spanish hospital. Int Ophthalmol. 2016;36(2):185-194.

3. LiY, Lin Z, Shi X, et al. Retrospective analysis of 15 cases of Penicillium marneffei infection in HIV-positive and HIV-negative patients. Microb Pathog. 2017;105:321-325.

4. Takezawa Y, Shiraishi A, Noda E, et al. Effectiveness of in vivo confocal microscopy in detecting filamentous fungi during clinical course of fungal keratitis. Cornea. 2010;29(12):1346-1352.

5. Garg A, Stuart A, Fajgenbaum M, Laidlaw DA, Stanford M. Chronic postoperative fungal endophthalmitis caused by Penicillium citrinum after cataract surgery. J Cataract Refract Surg. 2016;42(9):1380-1382.
6. Durand ML. Bacterial and fungal endophthalmitis. Clin Microbiol Rev. 2017;30(3):597-613.

7. Smith TC, Benefield RJ, Kim JH. Risk of fungal endophthalmitis associated with cataract surgery: a mini-review. Mycopathologia. 2015;180(5-6):291-297.

8. Sowmya P, Madhavan HN. Diagnostic utility of polymerase chain reaction on intraocular specimens to establish the etiology of infectious endophthalmitis. Eur J Ophthalmol. 2009;19(5):812-817.

9. Caggiano G, Napoli C, Coretti C, et al. Mold contamination in a controlled hospital environment: a 3-year surveillance in southern Italy. BMC Infect Dis. 2014;14:595.

10. Takayama K, Ogawa M, Mochizuki M, Takeuchi M. Cytomegalovirus retinitis in a patient with proliferative diabetes retinopathy. Ocul Immunol Inflamm. 2013;21(3):225-226.

11. Ogawa M, Sugita S, Watanabe K, Shimizu N, Mochizuki M. Novel diagnosis of fungal endophthalmitis by broad-range real-time PCR detection of fungal $28 \mathrm{~S}$ ribosomal DNA. Graefes Arch Clin Exp Ophthalmol. 2012;250(12):1877-1883.

12. Sugita S, Shimizu N, Watanabe K, et al. Diagnosis of bacterial endophthalmitis by broad-range quantitative PCR. Br J Ophthalmol. 2011;95(3):345-349.

13. Limper AH, Adenis A, Le T, Harrison TS. Fungal infections in HIV/ AIDS. Lancet Infect Dis. 2017.

14. O'Day DM, Head WS, Robinson RD, Stern WH, Freeman JM. Intraocular penetration of systemically administered antifungal agents. Curr Eye Res. 1985;4(2):131-134.
International Medical Case Reports Journal

\section{Publish your work in this journal}

The International Medical Case Reports Journal is an international, peer-reviewed open-access journal publishing original case reports from all medical specialties. Previously unpublished medical posters are also accepted relating to any area of clinical or preclinical science. Submissions should not normally exceed 2,000 words or

\section{Dovepress}

4 published pages including figures, diagrams and references. The manuscript management system is completely online and includes a very quick and fair peer-review system, which is all easy to use. Visit $\mathrm{http}: / /$ www.dovepress.com/testimonials.php to read real quotes from published authors.

Submit your manuscript here: https://www.dovepress.com/international-medical-case-reports-journal-journal 